\title{
Desejos de voz e palavra em Ditos e Malditos
}

\section{Resumo}

Neste artigo proponho uma reflexão sobre a utilização da voz, das palavras e textos na criação coreográfica contemporânea, tendo como referência a obra Ditos e Malditos: Desejos da Clausura, do Terpsí Teatro de Dança.

Palavras-chave: criação coreográfica contemporânea: voz; palavra; texto; Terpsí Teatro de Dança

\section{Voice and Words Desires in Ditos e Malditos}

\section{Abstract}

This paper aims to reflect on the use of voice, words and texts in contemporary choreography, with reference to the work Ditos e Malditos: Desejos da Clausura, from Terpsí Teatro de Dança.

Keywords: contemporary choreography; voice; word; text; Terpsí Teatro de Dança

\section{Introdução}

O espetáculo Ditos e Malditos: Desejos da Clausura (2009), do Terpsí Teatro de Dança, originou-se de um trabalho anterior do grupo, Ditos e Malditos - Uma instalação Coreográfica (2008). Ambos se inspiraram no cruzamento entre fragmentos de textos de artistas considerados transgressores ou malditos (Alfred Jarry, Augusto dos Anjos, Caio Fernando Abreu, Edgar Allan Poe, Marcel Duchamp, Samuel Beckett, Vincent Van Gogh) com alguns ditos populares. Os desejos da clausura vieram para aprofundar as especulações acerca da utilização de textos e palavras como propulsores para a criação de partituras coreográficas. Assim, ao longo do espetáculo textos, frases, palavras, gritos, murmúrios alternam-se com uma ambiência musical, formando um tecido sonoro que modula a encenação, conferindo-Ihe gravidade, leveza, intensidade. E, por vezes, acentuando ou pontuando sentidos e significados.

Neste artigo proponho uma reflexão sobre a utilização do texto, da voz e da palavra em Ditos e Malditos: Desejos da Clausura, buscando compreender como tais

\footnotetext{
1 Doutora em Estudos e Práticas Artísticas pela Université du Québec à Montreal. Professora Adjunta na Universidade Federal do Rio Grande do Sul.
} 
elementos contribuem para a construção da cena e, principalmente, como contribuem ou não para a elaboração de sentidos coreográficos nesta obra. Se, como aponta Lehmann (2007), a dança não formula sentido, mas articula energia, proponho a noção de sentido coreográfico como o que só pode existir enquanto movimento e/ou sua ausência, como modulação da energia no corpo, como uma qualidade própria ao dançante ou coreográfico. Nesse sentido, estou de acordo com Fèbvre (1995), quando a autora define qualidade dançante como aquela engendrada por um tipo particular de gestão da corporeidade que se manifesta nas atividades multiformes e desinteressadas a priori do processo de significação. Surge da transformação permanente do corpo que se move motivado mais por uma pulsão autorreflexiva, relacionada prioritariamente a produzir sensações e a desfrutá-las, ao invés de se inclinar sobre os sentidos ou sobre a representação. Tenho também por propósito compreender como a voz, as palavras e textos se articulam com o corpo em movimento, engendrando - ou não - corporeidades dançantes diversas das que povoavam os trabalhos anteriores do Terpsí Teatro de Dança.

Proponho um enfoque no limiar da intimidade, pois tenho atuado como intérprete em dança contemporânea em Porto Alegre, desde os anos 1980. Embora nunca tenha dançado no Terpsí, tenho assistido a seus espetáculos desde a estreia do grupo, em 1987, com As quatro estações. Do mesmo modo, venho acompanhando a produção em dança contemporânea em Porto Alegre, no Brasil e no mundo, sempre que isso se torna possível. Como pesquisadora, venho elegendo temas enraizados na minha experiência com dança, privilegiando o estudo dos processos de criação coreográfica e suas relações com a construção de corpos dançantes (DANTAS, 2005, 2011). A utilização da voz e da palavra na coreografia contemporânea tem me interessado na medida em que me debruço, como pesquisadora, sobre obras que se servem desses elementos (DANTAS, 2010) e na medida em que, em cena como bailarina, venho falando cada vez mais.

Já há algum tempo, a criação coreográfica contemporânea tem utilizado o texto, a palavra, a voz e outros fenômenos de vocalização como elementos de construção da cena e da própria coreografia. No entanto, ainda nos anos 1930, Valeska Gert, bailarina alemã, criava o solo Diseuse, no qual gritos, sussurros e palavras permeavam e estruturavam sua dança (FÉBVRE, 1995). No final dos anos 1970 estes elementos se tornam mais presentes em trabalhos de diferentes coreógrafos. Pina Bausch 
e o Tanztheatre Wuppertal, em obras como Kontakhof (1978) e Nelken (1982), entre outras, colocam em evidência a palavra e o texto como elementos da coreografia, através de narrativas orais nas quais os bailarinos se apresentam seguidamente ao público pelo seu nome verdadeiro, na sua língua materna, e contam histórias que poderiam ser autobiográficas, mas nem sempre o são. Já Trisha Brown, em Accumulation with Talking plus Water Motor (1979) retoma seus dois solos antológicos - Accumulation (1971) e Water Motor (1978) - conjugando movimentos com descrições de fatos ocorridos durante outras apresentações das coreografias. Neste trabalho, a palavra é dança, participa da gestão da energia no corpo que se move, o conteúdo linguístico modula o dançante e é modulado por ele.

A partir dos anos 1990, os sons emitidos pelos bailarinos tornam-se constantes em inúmeras criações contemporâneas de diferentes locais, seja sob a forma de suspiros, sussurros, respirações ofegantes, sons amplificados em cena ou sob a forma de palavras e textos mais ou menos estruturados. Como ressalta Fèbvre (1995), o uso da voz e da linguagem opera em cena uma mutação do visível. Analisando os fenômenos de vocalização presentes na criação contemporânea em dança, esta autora ressalta as múltiplas possibilidades de utilização da voz e da palavra e seus efeitos na obra coreográfica. No entanto, esses diferentes modos de articulação da palavra e da voz não são excludentes e podem coexistir numa mesma obra.

A voz pode ser utilizada como ampliação da respiração, emergindo da gestão dos ruídos e sons provenientes do ato de respirar, potencializados pelo esforço do corpo que dança. Essas sonoridades surgem como um prolongamento do corpo dançante, acentuando sua expressividade fundamental. Como sublinha Fèbvre (1995), é como se o corpo dançante se deixasse transbordar por suas funções orgânicas ou por suas pulsões, o que acaba por dramatizá-lo, mesmo que o contexto coreográfico não seja aquele do drama.

Outra possibilidade de emprego da voz é como partitura rítmica ou melódica. Nesse caso, a voz está a serviço da produção de uma musicalidade que impregna o corpo dançante e que suscita variações rítmicas nos seus movimentos. Muitas vezes a voz sustenta ou pontua o movimento, compartilha de seu trajeto espacial e energético por meio de suas variações de altura e timbre. A palavra pode surgir nesse jogo, mas o ritmo e a melodia é que são protagonistas 
A palavra também se faz presente de diferentes maneiras. Destacando seu uso entre oralidade e linguagem, Fèbvre (1995) destaca a utilização de línguas inventadas ou estrangeiras em diversas obras coreográficas. Desse modo, a palavra é explorada como materialidade sonora, expressiva e simbólica, escapando à função de transmissão de conteúdo, mas agindo como simulacro de uma permuta comunicacional. Os sentidos são muitas vezes percebidos mais pela modulação e singularidade fonética do que pelo uso de códigos sintáxicos e semânticos. De modo semelhante, a palavra, discreta ou ambígua, quase inaudível, aparece como vocalização de acompanhamento: "[...] murmurada ou cochichada, sem projeção, a palavra parece fazer parte da intimidade dos bailarinos" (p. 104). Para o espectador, é inútil tentar compreender o que se diz em cena e os murmúrios dispersam o sentido.

Num outro registro, aparece o uso de textos, discursos e monólogos sob a forma de comunicação direta com o público. Muitas vezes, os textos não se enquadram numa ação dramática, ao contrário, parecem se subtrair à representação. Em Ditos e Malditos: Desejos da Clausura, a voz e a palavra aparecem, predominantemente, através de fragmentos de textos proferidos sob a forma de comunicação direta com o público. Desde o início do espetáculo, um bailarino - Raul Voges - atua como uma espécie de mestre de cerimônias. E é dele a prerrogativa da palavra.

\section{Prólogo}

Antes de entrar na sala de espetáculo, cada espectador é convidado a escolher o retrato de um artista maldito e a responder no verso do retrato à questão "Qual é o seu desejo?" para, logo após, depositar este papel numa gaiola de madeira.

Entrando na sala, vê-se no canto superior esquerdo da plateia Raul Voges, que recepciona o público. Ele canta, desce as escadas, dirige-se sorrindo às pessoas que estão chegando, mostra-se sedutor e inicia sua fala: "Olha essa roda que gira e que cai, olha essa massa cinzenta que sai, olha esse sangue que escorre e se vai[...]". Caminhando com o corpo recurvado, dirige-se ao canto esquerdo do palco, abre uma cortina e acende uma luz. Surge um chuveiro do qual pendem correntes iluminadas e ele recomeça:

O guerreiro está ferido. E não monta. Nem mesmo experimento a vontade de evocar o meu passado. Isso me entendia. Eu continuo, continuo. É tudo. Minhas memórias estão congeladas. [...]. Dito e feito. Eu lavo as minhas mãos. 
A cena, que dura aproximadamente cinco minutos, termina em um blackout. Nela, diretora e bailarino delineiam os traços de uma personagem e, através dela, estabelecem o lugar e o modo de apresentação e manifestação do texto durante o espetáculo. Os instantes falados se presentificam sob a forma de monólogos e de pequenas frases dirigidas aos espectadores. O monólogo, segundo Pavis (2007), é um discurso de uma só pessoa. Diferencia-se do diálogo pela "ausência de intercâmbio verbal e pela grande extensão de uma fala destacável do contexto conflitual e dialógico" ( $p$. 247). Ele dirige-se ao espectador, interpela-o como cúmplice e voyeur. Para o autor, esta comunicação direta constitui a força e ao mesmo tempo a inverossimilhança do monólogo. Por isso, ele pode revelar a artificialidade teatral e as convenções de jogo. Fébvre (1995) destaca que em boa parte da produção coreográfica contemporânea há uma predileção pelo uso da palavra sob a forma de comunicação direta com o público. Deste modo, os bailarinos não utilizam os textos para se comunicarem entre si, conforme as convenções do teatro dramático tradicional. Como precisa a autora, na comunicação direta com o público, "a dramatização é parcialmente desfeita e a linguagem passa a ter a função de apelar ao espectador e de incluí-lo na cena" (p. 107).

Essa estrutura se repete na maior parte das vezes em que o texto retorna à cena. Ao longo do espetáculo, cenas coreográficas alternam-se com momentos falados, cujos textos são geralmente proferidos por Raul Voges. Próximo ao final da coreografia há uma cena em que Suzana Schoellkopf retira de uma caixa e lê os textos que revelam os desejos depositados pelos espectadores antes do início da apresentação, utilizando um microfone. Nesse momento, intensifica-se ainda mais a relação com o público, que se torna testemunha e cúmplice de seus próprios desejos. No entanto, conforme o espetáculo se desdobra, os textos vão se tornando mais rarefeitos.

Conforme anunciado no programa do espetáculo, os textos são compostos por fragmentos e/ou referências a algumas obras dos escritores malditos misturados a ditos populares. Embora não contem uma história, por vezes os textos adquirem algum valor semântico, até porque os ditos são reconhecidos pelo público, aludem aos temas propostos e induzem a uma certa familiaridade. Mesmo não havendo um sentido unívoco para a significação (como aliás nunca há), as falas instalam uma atmosfera e estabelecem um ponto de partida para a peça. Como diria Fèbvre (1995), servem de ancoragem para possíveis sentidos e significados. 


\section{Corpos silenciosos}

A cena seguinte se inicia ao som de pingos de água, com a entrada de Ângela Spiazzi no proscênio, portando uma lanterna, iluminando o chão e as lâminas de alumínio que impedem a visão do palco. A bailarina abre as lâminas e revela o espaço estruturado por uma cortina de plástico transparente. A ação é acompanhada por uma ambiência musical densa e uma voz em off pouco audível. Ângela retira a cortina e pode-se ver uma figura feminina sentada numa cadeira de balanço. A ambiência sonora vai se tornando mais musical. Os bailarinos entram e saem de cena, enquanto retratos dos artistas malditos caem do teto. Movimentações em círculo, cirandas, música medieval, cada vez mais rápidas. Pausa. Ângela fecha as lâminas. Ouve-se Raul Voges que canta.

A ação de limpar é constante ao longo da peça, assim como o abrir e fechar das lâminas. Geralmente, o abrir das lâminas revela uma nova estrutura, novos cenários e objetos em cena, nova ambiência sonora e novas organizações coreográficas. Alternam-se, assim, coreografias em solos, em duos, em trios, em grupo, acompanhadas, na sua maioria, de música. Há poucos momentos de silêncio no espetáculo: um tecido sonoro, geralmente formado por uma música ou pela justaposição de músicas, percorre a cena o tempo todo, organizando o fluxo de movimentos e pontuando a ação.

Geralmente, quando o texto aparece, o volume da música diminui. Como na cena em que, ao som de um blues, após descer de uma caixa instalada no teto, Raul Voges é erguido e manipulado por Gelson Farias e Edson Ferraz. Como se caminhasse com os pés apoiados nas mãos dos bailarinos, Raul fala no ritmo da música:

Tenho tentado aprender a ser humilde, a engolir os nãos que me enfiam goela abaixo, a lamber o chão dos palácios, a ser desprezado como um cão e... tudo bem. Acordar, escovar os dentes, tomar um café... E continuar e continuar e continuar (...)

Da repetição do verbo continuar depreende-se uma partitura de movimentos sinuosos, dançada até o final da música. Nesse momento, parece que as palavras, junto com a música, servem de impulso para o movimento. A palavra modula o corpo dançante, o corpo dançante torna-se emissor da voz. Há uma interdependência entre a voz, a palavra e o corpo em movimento e o texto serve de partitura melódica, tornando-se um elemento da coreografia. Evocando Pavis (2008), pode-se dizer que há efeito de sincronização entre o texto, a música e o movimento: cada sistema significante tende a coincidir em seu ritmo com os outros. 
A próxima cena ocorre ao som de uma música eletrônica. Gabriela Peixoto e Francini Pressi calçam luvas de cirurgia em Raul Voges. Ângela Spiazzi Ihe entrega um charuto. Fumando, Raul fala: "Arquivo. Abrir janela. Adicionar favoritos. Minimizar". Enquanto isso, as bailarinas colocam lupas em cada um dos seus olhos e, a seguir, no púbis. Avançando para o proscênio, o bailarino prossegue: "Cansaço de ser cínico. Miséria é a miséria dos afetos. Estamos esgotados. A invenção é a potência do homem comum[...]"'Aqui, como no prólogo, o bailarino dirige-se diretamente aos espectadores.

As bailarinas, embora participem da cena manipulando objetos que se transformam em acessórios e enfeitam o corpo de Raul, permanecem silenciosas neste momento. Por que a fala é privilégio desse bailarino? Por que os demais bailarinos e bailarinas estariam calados? O silêncio delas reafirmaria uma tradição clássica, segundo a qual o corpo dançante deveria ser imponderável, leve, treinado para não produzir ruídos oriundos do deslocamento do seu peso? A economia de falas atribuída às intérpretes - Gabriela Peixoto e Ângela Spiazzi dizem apenas uma frase cada uma - poderia também reafirmar uma tradição da dança moderna, na qual a expressão de emoções se faz principalmente através de torções e contrações, retenção e expansão do corpo. Apesar de reintegrar ao corpo dançante a inspiração e expiração profundas, tornando por vezes esse jogo audível para os espectadores, a dança moderna concedeu pouco espaço à palavra, reforçando, ao seu modo, a mudez do bailarino.

No entanto, conceder a palavra a apenas um dos bailarinos pode ter sido uma escolha da coreógrafa para dar relevância à dança, que emanaria principalmente dos corpos dos outros intérpretes. E, dessa maneira, sublinhar que o corpo em movimento, na sua relação com os objetos, com o espaço e com a trama sonora seria a matéria privilegiada para a criação da obra e de seus possíveis sentidos. Sendo assim, o corpo dançante em Ditos e Malditos: Desejos da Clausura seria eloquente já na sua presença, prescindindo da voz e da palavra?

\section{Corpos eloquentes}

No fundo do palco, ao som de uma música em compasso ternário, cantada em inglês, no alto de uma larga escada, há uma figura feminina - Suzana Schoellkopf com um serrote em cada mão. Embalada pela música, ela desce as escadas, tronco curvado, movimentando os braços, às vezes golpeando um serrote contra o outro, produzindo um ruído metálico. Os serrotes são como prolongamentos de seus membros. 
Retornando à escada, Suzana larga os serrotes. Ângela Spiazzi os recolhe do chão e inicia uma dança com eles, mas é interrompida por Raul Voges, que anuncia: "Alto lá! E o corvo disse nunca mais." Gabriela Peixoto, fala, com voz aguda, como se fosse uma criança: "Ele disse nunca mais. Ele disse nunca mais".

$\mathrm{Na}$ última cena do espetáculo, após momentos de intensa movimentação, ao som de música densa, faz-se silêncio. Recomeça o som dos pingos de água, presentes no início espetáculo. Ângela Spiazzi fecha as lâminas de alumínio e diz: "Mais uma vez.' Abre-as novamente e vê-se uma estrutura arredondada, na qual a bailarina vai sentar-se, como se fosse em uma cadeira de balanço. Ela efetivamente se embala e repete: "Mais uma vez". Ao fundo, ruídos metálicos e uma voz em off que narra um texto pouco compreensível. Ao som de uma valsa, Ângela dança. A princípio no chão, passando para a cadeira, ela emite um grito. Salta, gira, esboça passos de valsa, desliza para o chão, vira a cadeira ao contrário. Subindo nas suas laterais, equilibra-se em um dos pés, quando a música está no seu ápice. Desce, faz o objeto retornar à posição de início, sobe novamente na cadeira, embalando-se em pé. Suzana lhe alcança os serrotes, um em cada mão, que ela abana como se fossem asas. Fecham-se as lâminas de alumínio. Ela parece rir.

Essas duas cenas servem de pretexto para pensar sobre a eloquência do corpo dançante num espetáculo de dança que se propõe a utilizar textos como ponto de partida para a criação coreográfica.

Parece-me que em Ditos e Malditos: Desejos de Clausura, a voz, a palavra e o texto não induzem a alterações nas qualidades dos movimentos, não se infiltram nos corpos dos bailarinos a ponto de produzir ações, gestos e movimentos radicalmente diferentes daqueles que povoam outras obras do TerpsíTeatro de Dança. A eloquência dos corpos dançantes, principalmente destas duas bailarinas, vem do longo tempo em que se dedicam a colaborar com Carlota Albuquerque na criação de suas obras. Ao mesmo tempo em que cultivam suas características pessoais, Ângela e Suzana estão à escuta de outros corpos, prontas para responder aos estímulos do ambiente e a se concentrar nas ações a cumprir. Se por vezes podem se portar como instrumentos da vontade da coreógrafa, por outro lado reapropriam-se dessa vontade. Interrogando seus desejos, fazem de seus corpos o terreno mais propício para as investigações que a companhia tem realizado. 
Desse modo, Suzana Schoellkopf mostra-se eloquente nos seus gestos amplos, nos seus braços que se prolongam nos serrotes, na criação e projeção de um espaço próprio que avança plateia adentro, no seu grito histriônico, nas suas gargalhadas. Da mesma forma age Ângela Spiazzi, através da precisão e da contenção de seus gestos, no seu grito contido, na sua risada esboçada. Ambas encarnam radicalmente o sentido do adjetivo eloquente: aquele que domina o ânimo de quem o ouve. Nesse caso, de quem testemunha essas presenças.

\section{Considerações Finais}

Palavras, frases, textos e canções em de Ditos e Malditos: Desejos da Clausura não têm por propósito organizar uma narrativa linear nem propor uma explicitação de conteúdos. Os elementos textuais e vocais estão presentes sob o modo de justaposição, sem contribuir para explicitar um conteúdo global. Voz, palavra, texto, ruídos, música combinam-se com o cenário, figurino, objetos, gestos, movimentos, partituras coreográficas e contribuem para instaurar atmosferas específicas, mas não são necessariamente preponderantes na criação destas atmosferas. Muitas vezes, o texto serve para acentuar a sensação de descontinuidade e ruptura da ação. $O$ texto é um elemento na composição da obra, que vai se tornando rarefeito na medida em que o espetáculo se desenvolve. Podemos observar ainda que, como sugere Fèbvre (1995), o murmúrio da linguagem poderia também multiplicar os corpos, criar relações inesperadas no espaço entre corpos, música, som e movimento.

Neste espetáculo, a voz, a palavra e o texto não provocam alterações radicais nas partituras coreográficas, nem nas corporeidades e gestualidades características da companhia de Carlota Albuquerque. Dessa forma, o texto não impõe uma mutação do coreográfico, ele é um dos dispositivos utilizados para reforçar o ambiente da cena, sem provocar uma redução da qualidade dançante. Como ressalta Fèbvre (1995), por perda da qualidade dançante é preciso compreender o que, no tratamento da corporeidade, quebra total ou parcialmente a mobilidade dançante e se inscreve, potencialmente, no campo da representação mimética. Em Ditos e Malditos: Desejos da Clausura, a palavra não pretende direcionar o imaginário do espectador. Não há um terrorismo naif da intencionalidade, mas a palavra emitida em cena projeta pontos de ancoragem do sentido. O texto dito por vezes contamina a dança com o peso informa- 
tivo e emocional que ele porta, mas não se sobrepõe ao coreográfico. A palavra não é mais eloquente do que os corpos dançando.

\section{Referências bibliográficas}

DANTAS, Mônica. "De que são feitos os dançarinos de "aquilo...: criação coreográfica e formação de intérpretes em dança contemporânea." Revista Movimento, v. 11, n. 2, p. 31-57, maio/agosto 2005.

DANTAS, Mônica. "Voz e palavra na criação coreográfica contemporânea." Anais do VI Congresso de Pesquisa e Pós-Graduação em Artes Cênicas. 2010. Disponível em http:// portalabra2. dominiotemporario.com/memoria1/?p=1224

DANTAS, Mônica. "Corpos em trânsito, corpos antropofágicos: criação coreográfica e construção de corpos dançantes em Marché aux puces." In:NORA, Sigrid (org.). Húmus, v. 4, 2011, p. 13-23.

FEBVRE, Michèle. Danse contemporaine et théâtralité. Paris: Chiron, 1995.

FERRAZ, Wagner. Ditos e Malditos: Desejos da Clausura - Processo de criação da Terpsí Teatro de Dança. Wagner Ferraz: Porto Alegre, 2009.

LEHMANN, Hans-Thies. Teatro Pós-dramático. São Paulo: Cosac\&Naify, 2007.

PAVIS, Patrice. Dicionário de Teatro. São Paulo: Perspectiva, 2007.

PAVIS, Patrice. A Análise dos Espetáculos: teatro, mímica, dança, dança-teatro, cinema. São Paulo: Perspecitva, 2008. 